\title{
ANALISIS PRODUKTIVITAS, KEUNTUNGAN, DAN EFISIENSI BIAYA USAHA BUDIDAYA LEBAH MADU Trigona sp. DI KECAMATAN LANDONO KABUPATEN KONAWE SELATAN
}

\author{
Ni Putu Arin Pratiwi ${ }^{1 *}$, Bahari Abdullah ${ }^{1}$, Muhammad Arief Dirgantoro ${ }^{1)}$ \\ ${ }^{1} J u r u s a n$ Agribisnis Fakultas Pertanian Universitas Halu Oleo Kendari Indonesia 93232
}

${ }^{*}$ Corresponding author : putuarinpratiwi3422@gmail.com

To cite this article:

Pratiwi, N., Abdullah, B., \& Dirgantoro, M. (2020). Analisis Produktivitas, Keuntungan, dan Efisiensi Biaya Usaha Budidaya Lebah Madu Trigona sp. di Kecamatan Landono Kabupaten Konawe Selatan. Jurnal IImiah Membangun Desa dan Pertanian, 5(3), 111 - 116. doi:http://dx.doi.org/10.37149/jimdp.v5i3.11026

Received: February 13, 2020; Accepted: June 22, 2020; Published: June 28, 2020

\begin{abstract}
This study aims to determine the productivity of Trigona sp beekeeping, know the benefits of Trigona $s p$ beekeeping and find out the cost efficiency of Trigona $s p$ beekeeping in Landono Subdistrict, Konawe Selatan Regency. This research was conducted in November 2019 to March 2020 using quantitative descriptive methods. Analysis of the data used in this research is productivity analysis, profit analysis, and cost efficiency analysis using the RC ratio. The results obtained, the average value of honey bee productivity in each bee colony produces $1.02 \mathrm{~kg}$ of honey, the average profit of Trigona sp beekeeping is Rp5,068,900, - and RC The average ratio of Trigona sp beekeeping is 3.01. $\mathrm{RC}$ ratio value $>1$ which indicates that the Trigona sp honey beekeeping business is profitable and can be continued. Based on this research it is expected that the Trigona sp bee business can be better known and developed more broadly.
\end{abstract}

Keywords:cost efficiency; productivity; profits; Trigona sp.

\section{PENDAHULUAN}

Indonesia sebagai negara agraris memiliki sumber daya alam yang melimpah, kekayaan alam ini dapat memberi keuntungan baik secara finansial maupun dalam menjaga kelestarian alam. masih melimpah salah satunya adalah sumber daya yang berasal dari hutan. Hutan merupakan sumber daya penghasil kayu terbesar yang dapat dimanfaatkan oleh masyarakat. Selain sebagai penghasil kayu, hutan juga menghasilkan produk hutan non kayu. Hasil hutan non kayu yang umumnya dikelola dan dimanfaatkan oleh masyarakat adalah cendana, sagu, rotan, aren,sukun, bambu, sutera alam, jernang, kemenyan, kayu putih, aneka tanaman obat, minyak atsiri dan madu. Madu merupakan salah satu hasil hutan non kayu yang memiliki harga ekonomi tinggi dan banyak dijadikan sebagai sumber mata pencaharian oleh masyarakat pedesaan (Suhesti \& Hadinoto, 2015). Lebah madu yang populer diusahakan sebagai penghasil madu di Indonesia adalah Apis dorsata yang merupakan lebah lokal dan Apis melifera yang merupakan lebah unggulan dari Australia dengan nama lengkap Apis Mellifera vas Ingustica SPIN . Namun saat ini lebah Trigona sp. mulai banyak dikenal dan budidayakan oleh peternak (Jaya, 2017).

Sulawesi Tenggara dalam memproduksi hasil hutan non kayu berupa madu lebah Trigona $s p$. masih terbilang sangat sedikit. Menurut Kelompok Kerja Jabatan Fungsional Penyuluhan Dinas Kehutanan Sulawesi Tenggara, produksi madu di Sulawesi Tenggara hanya di sumbangkan oleh 3 kabupaten yang terdiri dari Kabupaten Konawe, Konawe Selatan dan Bombana. Dari 3 Kabupaten tersebut, penyumbang produksi madu terbesar adalah Kabupaten Konawe Selatan dengan jumlah produksi sebesar $1.500 \mathrm{~kg}$, untuk Kabupaten Konawe menghasilkan produk madu sebesar $330 \mathrm{~kg}$ sedangkan Kabupaten Bombana hanya menghasilkan produksi madu sebesar $50 \mathrm{~kg}$. Salah satu Kecamatan di Kabupaten Konawe Selatan sebagai tempat pembudidayaan lebah Trigona sebagai penghasil produk madu yang telah berkembang hingga saat ini adalah Kecamatan Landono.

Lebah Trigona yang biasa disebut Klanceng memiliki keistimewaan yaitu tidak memiliki sengat, memiliki zat perekat seperti lem sebagai senjata untuk melindungi sarangnya, dan bentuknya 
kecil-kecil sehingga mudah dibudidayakan untuk menghasilkan keuntungan (Warisno, 1996). Usaha budidaya berupa Produktivitas stup usaha budidaya lebah madu oleh peternak belum pernah dilakukan perhitungan produktivitas madu yang diperoleh per stup. Adanya usaha budidaya yang dilakukan dengan memproleh produksi maka yang diharapkan adalah prolehan keuntungan dari hasil penjualan produk. Menurut (Ichwan et al., 2016) kotak stup yang dibuat harus sesuai dengan ukuran besarnya koloni lebah, semakin besar ukuran koloni lebah maka semakin besar kotak stup yang digunakan. Sehingga, ukuran stup yang tidak sesuai akan mempengaruhi produktivitas madu. Pemecahan koloni mendapat dilakukan pada koloni lebah yang terlalu besar agar lebah dapat berkembangbiak dengan baik dalam kotak stup yang telah disediakan. Menurut (Fadhilah \& Rizkika, 2015), lebah tanpa sengat (Trigona) kurang diminati untuk dibudidayakan karena produktivitas lebah tanpa sengat lebih rendah ketimbang lebah madu biasa. Namun, karena rasa rasa asam yang terkandung dalam madu Trigona serta banyaknya khasiat dari madu lebah ini, sehingga harga jual madu lebah Trigona lebih tinggi dibandingkan madu jenis lain. Suatu usaha budidaya menguntungkan jika proporsi penerimaan jauh lebih besar dengan penggunaan biaya. Proporsi penerimaan dalam usaha budidaya lebah madu berbeda-beda antar lokasi budidaya. Menurut (Rahmayanti et al., 2018), usaha budidaya lebah madu Trigona sp. tidak selalu berjalan dengan baik. Hal ini oleh beberapa kendala yang dialami pembudidaya dalam proses budidaya seperti ketersediaan pakan, berubahubahnya iklim, kurangnya keterampilan dan modal sehingga mempengaruhi proses produksi hingga keuntungan yang diperoleh peternak. Selanjutnya, kelayakan usaha pada usaha budidaya lebah madu Trigona perlu untuk dianalisis untuk mengetahui keberlanjutan usaha budidaya. Kelayakan usaha yang dilihat melalui efisiensi biaya melalui perbandingan proporsi penerimaan dan penggunaan biaya dalam kegiatan usaha. Penelitian ini dilakukan dengan tujuan untuk Menganalisis besarnya produktivitas stup usaha budidaya lebah madu Trigona $s p$, menganalisis besarnya keuntungan usaha budidaya lebah madu Trigona $s p$. dan menganalisis efisiensi biaya usaha budidaya lebah madu Trigona sp. di Kecamatan Landono Kabupaten Konawe Selatan.

\section{MATERI DAN METODE}

Kecamatan Landono Kabupaten Konawe Selatan menjadi lokasi penelitian ini yang ditunjuk langsung atau ditentukan dengan sengaja (purposive). Penelitian ini dilakasanakan pada November 2019 hingga Maret 2020. Analisis data yang digunakan untuk mengetahui produktivitas stup usaha produk madu lebah Trigona sp. digunakan rumus yang dikemukakan oleh (Martono, 2019) sebagai berikut:

Keterangan:

$$
\text { Produktivitas }=\frac{\text { Output }}{\text { Input }}
$$

Output = Jumlah produksi madu yang dihasilkan $(\mathrm{Kg})$

Input = Jumlah kotak stup yang menghasilkan madu (stup)

Analisis keuntungan menggunakan rumus yang dikemukakan oleh (Soeharno, 2007) sebagai berikut:

Keterangan:

$$
\begin{array}{ll}
\pi & =\text { TR-TC } \\
\text { TR } & =\mathrm{p} \times \text { Py } \\
\text { TC } & =\text { TFC }+ \text { TVC }
\end{array}
$$

$\pi \quad=$ Keuntungan (Profit)

$\mathrm{TR}=$ Penerimaan total $(\mathrm{Rp})$

TC = Biaya total selama kegiatan produksi $(\mathrm{Rp})$

$\mathrm{p} \quad=$ Produksi yang diperoleh selama periode produksinya $(\mathrm{Kg})$

Py $\quad=$ Harga dari hasil produksi $(\mathrm{Rp})$

TFC = Jumlah biaya tetap usaha dalam satu periode $(R p)$

TVC = Jumlah biaya variable usaha dalam satu periode (Rp)

Analisis efisiensi biaya usaha produk madu lebah Trigona $s p$. digunakan rumus yang dikemukakan oleh (Soekartawi, 2003) sebagai berikut:

Keterangan:

$$
\mathrm{RC} \text { ratio }=\frac{\mathrm{TR}}{\mathrm{TC}}
$$

$\mathrm{RC}$ ratio $=$ Revenue Cost Ratio

TR = Total Penerimaan (Total Revenue)

TC $=$ Total Biaya (Total Cost) 
Penentuan kriteria pengambilan keputusan:

- $\mathrm{RC}$ ratio $\geq 1$ maka penggunaan biaya produksi usaha produk madu Trigona sp. menguntungkan dan layak dilanjutkan

- $\mathrm{RC}$ ratio $\leq 1$ maka penggunaan biaya produksi usaha produk madu Trigona $s p$. tidak menguntungkan dan tidak layak dilanjutkan

- $\mathrm{RC}$ ratio $=1$ maka penggunaan biaya produksi usaha produk madu Trigona sp. (impas)

\section{HASIL DAN PEMBAHASAN}

\section{Karakteristik Responden}

Karakteristik responden dalam penelitian ini dibagi menjadi empat karakteristik yaitu umur, pendidikan, jumlah tanggungan keluarga dan pengalaman usaha, seperti pada Tabel 1

Tabel 1. Karakteristik peternak lebah Trigona sp. di Kecamatan Landono, Tahun 2019

\begin{tabular}{lccc}
\hline \multicolumn{1}{c}{ Karakteristik } & Nilai & Rata-Rata & Persentase \\
\hline Umur (Tahun) & 9 & & 100 \\
18-65 & & 43 & 11 \\
\hline Pendidikan & 1 & & 33 \\
SD & 3 & - & 44 \\
SMP & 4 & & 11 \\
SMA & 1 & & 67 \\
Sarjana & & & 33 \\
Jumlah Tanggung Keluarga (Orang) & 6 & 3 & 11 \\
$<5$ & 3 & & 67 \\
$>5$ & 1 & & 22 \\
\hline Pengalaman Usaha (Tahun) & 6 & 10 & \\
$<5$ & 2 & &
\end{tabular}

Sumber: Data Primer Diolah, 2020

Tingkat umur responden akan mempengaruhi kemampuan fisik untuk bekerja dan cara berfikir yang semakin lambat dalam pengambilan keputusan (Firmansyah, 2015). Usaha budidaya lebah madu Trigona $s p$. di Kecamatan Landono dikelola oleh peternak yang masih dalam usia produktif dengan kekuatan fisik yang tinggi dan cenderung mengikuti perubahan. Hal tersebut dapat dibuktikan dengan hasil penelitian menunjukkan bahwa pada usaha produk madu di Kecamatan Landono sebanyak 9 orang yakni $100 \%$ dalam usia produktif. Pendidikan pada umumnya akan mempengaruhi pola pikir petani dalam pengambilan keputusan. Tingkat pendidikan peternak budidaya di Kecamatan Landono tergolong tingkat pendidikan menengah, namun tingkat pendidikan tidak menjadi penghambat oleh peternak budidaya dalam pengembangan budidaya lebah Trigona sp. karena, peternak lebah ini cukup berpengalaman. Jumlah tanggungan keluarga merupakan Jumlah anak dan anggota keluarga lain yang seluruh biaya hidupnya menjadi tanggung jawab responden yang diukur dengan satuan jumlah orang (Erlangga, 2016). Jumlah anggota keluarga yang sudah berada pada umur produktif memiliki peluang untuk meningkatkan pendapatan keluarga. Jumlah tanggungan keluarga pada responden di Kecamatan Landono bervariasi. Peternak lebah Trigona sp. dengan tanggungan keluarga di bawah 5 orang terdapat sebanyak 6 orang $(67 \%)$ sedangkan untuk tanggungan keluarga di atas 5 orang terdapat 3 orang (33\%). Pengalaman usaha yang dimiliki peternak sangat penting dan sangat berpengaruh terhadap keberlanjutan kegiatan budidaya yang dilakukan. Lama usaha adalah seberapa lama seseorang menekuni usaha yang telah dijalankan. Lama usaha yang dimaksud dapat diartikan sebagai sedikit banyaknya waktu yang digunakan untuk bekerja, semakin lama ia bekerja akan semakin besar juga pendapatannya (Setiaji \& Fatuniah, 2018). Peternak budidaya lebah Trigona sp. di Kecamatan Landono dominan berpengamalan dalam menjalankan kegiatan budidaya. Hal ini didukung dengan hasil penelitian yang menunjukkan bahwa kategori pengalaman usaha 5-10 tahun terdapat 6 orang (67\%), > 10 tahun terdapat 2 orang $(22 \%)$ dan pengalaman usaha paling rendah yaitu $<5$ tahun hanya terdapat 1 orang $(11 \%)$. 


\section{Produktivitas Stup Usaha Budidaya Lebah Madu Trigona sp.}

Produksi adalah banyaknya jumlah produk madu yang dihasilkan dari budidaya lebah Trigona $s p$. dalam satu kali panen $(\mathrm{Kg})$. Produksi lebah Trigona $s p$. berupa madu diproleh dari 5 rumah stup (bangsal). Kelima bangsal memiliki stup lebah sebanyak 113 stup. Jumlah stup yang dipanen sebanyak 297, menghasilkan produksi madu sebanyak $302 \mathrm{~kg}$ dalam 1 kali panen. Produksi madu pada stup dipengaruhi oleh kesediaan pakan disekitar lokasi budidaya. Kesediaan pakan yang melimpah dapat meningkatkan produksi madu karena kebutuhan nectar yang dibutuhkan lebah dalam memproduksi madu dapat terpenuhi. Usaha budidaya lebah madu Trigona dapat ditingkatkan dengan menanam tanaman yang memiliki kandungan nectar. Selanjutnya untuk lebih jelasnya dapat dilihat pada uraian tabel produktivitas. Dimana produktivitas adalah banyaknya madu yang diperoleh pada setiap stup pada usaha budidaya lebah madu Trigona ( $\mathrm{Kg} / \mathrm{Stup})$.

Tabel 2. Produktivitas madu per stup di Kecamatan Landono, Tahun 2019

\begin{tabular}{|c|c|c|c|c|c|}
\hline $\begin{array}{l}\text { Lokasi Bangsal } \\
\text { (Desa) }\end{array}$ & $\begin{array}{c}\text { Ukuran } \\
\text { Bangsal } \\
\left(\mathrm{m}^{2}\right)\end{array}$ & $\begin{array}{c}\text { Jumlah } \\
\text { Kotak Stup } \\
\text { (Stup) }\end{array}$ & $\begin{array}{c}\text { Jumlah Stup } \\
\text { Dipanen } \\
\text { (Stup) }\end{array}$ & $\begin{array}{l}\text { Produksi } \\
\text { Madu (Kg) }\end{array}$ & $\begin{array}{l}\text { Produktivitas } \\
\text { Stup (Kg/Stup) }\end{array}$ \\
\hline Wata Benua & 36 & 160 & 160 & 154 & 3,03 \\
\hline Lalonggapu & 20 & 105 & 90 & 108 & 1,20 \\
\hline Endanga & 20 & 48 & 47 & 40 & 0,85 \\
\hline Jumlah & 76 & 313 & 297 & 302 & 5,08 \\
\hline Rata-Rata & 25,33 & 62,60 & 59,40 & 60,40 & 1,02 \\
\hline
\end{tabular}

Sumber: Data Primer Diolah, 2020

Tabel 2. Produktivitas madu diperoleh dari jumlah stup yang dipanen dibagi dengan jumlah produksi madu sehingga menghasilkan produktivitas madu per stup pada koloni lebah. Produktivitas stup yang diperoleh akan bervariasi tiap musim panen, jika musim bunga mekar dengan kesediaan melimpah maka lebah dalam memproduksi madu bertambah. Menurut (Fadhilah \& Rizkika, 2015), produktivitas satu koloni Trigona sekitar $6,5 \mathrm{~kg}$ per tahun. Sedangkan berdasarkan analisis produktivitas pada stup lebah Trigona di Kecamatan Landono menghasilkan rata-rata produktivitas sebesar $1,02 \mathrm{~kg}$ maka dapat dikatakan bahwa produktivitas madu Trigona di Kecamatan ini masih dapat dikembangkan untuk mencapai produktivitas tertinggi. Selanjutnya berdasarkan penelitian (Rahmayanti et al., 2018) bahwa produksi madu per stup mencapai 0,16 L. produksi madu akan mempengaruhi produktivitas stup dalam menghasilkan madu. Produksi madu di setiap daerah berbeda, hal ini dipengaruhi oleh keterampilan peternak dalam membudidayakan lebah Trigona dengan keterbatasan informasi terkait dengan teknik budidayaa lebah madu Trigona yang masih sedikit.

\section{Keuntungan Usaha Budidaya Lebah Madu Trigona}

Analisis biaya penting diketahui dalam menganalisis keuntungan suatu usaha. Analisis biaya yang dimaksud dalam penelitian ini yaitu biaya variabel, biaya tetap dan total biaya. Biaya variabel yang dimaksud (biaya berubah) yaitu biaya yang dikeluarkan untuk memperoleh faktor produksi yang dapat diubah jumlahnya atau dapat juga dikatakan sebagai biaya yang dapat berubah dan dapat menentukan besar kecilnya produksi dengan melalui berbagai cara (Bambang \& Kartasapoetra, 1992). Biaya tetap adalah biaya yang dikeluarkan tidak berpengaruh pada besar produksi yang dihasilkan dalam kegiatan produksi. Biaya total adalah total keseluruhan dari biaya-biaya yang digunakan dalam proses budidaya dalam produksi madu Trigona. Lebih jelasnya analisis biaya dan keuntungan usaha budidaya lebah madu Trigona sp. dapat dilihat pada Tabel 3.

Tabel 3. Analisi biaya dan keuntungan usaha budidaya lebah madu Trigona sp. Tahun 2019

\begin{tabular}{|c|c|c|c|c|c|}
\hline $\begin{array}{l}\text { Lokasi Bangsal } \\
\text { (Desa) }\end{array}$ & $\begin{array}{c}\text { TVC } \\
\text { (Rp/Tahun) }\end{array}$ & $\begin{array}{c}\text { TFC (Rp/ } \\
\text { Tahun) }\end{array}$ & $\begin{array}{l}\text { TC }(\mathrm{Rp} / \\
\text { Tahun) }\end{array}$ & $\begin{array}{l}\text { TR }(\mathrm{Rp} / \\
\text { Tahun) }\end{array}$ & $\begin{array}{l}\text { Keuntungan } \\
\text { (Rp/ Tahun) }\end{array}$ \\
\hline Wata Benua & 4.788 .000 & 1.686 .500 & 6.474 .500 & 19.250 .000 & 12.775 .500 \\
\hline Lalonggapu & 2.776 .000 & 877.500 & 3.653 .500 & 13.500 .000 & 9.846 .500 \\
\hline Endanga & 1.640 .000 & 637.500 & 2.277 .500 & 5.000 .000 & 2.722 .500 \\
\hline Jumlah & 9.204 .000 & 3.201 .500 & 12.405 .500 & 37.750 .000 & 25.344 .500 \\
\hline Rata-Rata & 1.840 .800 & 640.300 & 2.481 .100 & 7.550 .000 & 5.068 .900 \\
\hline
\end{tabular}

Sumber: Data Primer Diolah, 2020 
Keuntungan merupakan perolehan bersih dari kegiatan usaha budidaya lebah pada KTH setelah dilakukannya pengurangan antara penerimaan total dan total biaya yang digunakan selama kegiatan produksi. Hal ini sesuai dengan pendapat (Tuwo, 2011) bahwa keuntungan adalah penerimaan dikurangi dengan biaya total, penerimaan diperoleh dari penjualan output dengan harga jual pada output. Penerimaan usaha produk madu dari ketiga desa dipengaruhi oleh jumlah produksi yang dihasilkan oleh masing-masing bangsal.

Tabel 3. menunjukkan bahwa biaya variabel rata-rata yang dikeluarkan per musim panen sebesar Rp1.840.800,- yang terdiri dari pengeluaran biaya bibit, biaya kemasan dan biaya tenaga kerja pencari koloni. Biaya tetap rata-rata yang dikeluarkan sebesar Rp 640.300,- per musim panen yang merupakan biaya penyusutan peralatan per tahun yang dikeluarkan oleh peternak. Menurut (Sukirno, 2013), biaya total adalah keseluruhan jumlah biaya tetap dan biaya variabel yang dikeluarkan suatu pemilik usaha untuk menghasilkan sejumlah keuntungan dalam periode tertentu. Biaya total rata-rata yang dikeluarkan sebesar Rp2.481.100,- yang merupakan penjumlahan antara biaya tetap dan biaya variabel. Selanjutnya dalam penelitian (Budiono, 2013), penerimaan merupakan hasil penjualan dari sejumlah output tertentu atau pembayaran yang diterima dari pihak lain. Penerimaan hasil usaha tergantung barang-barang yang dapat diklasifikasikan dan harga jual yang diperolehnya. Sejenis dengan pendapat (Soekartawi, 2016) bahwa penerimaan usahatani/peternak merupakan perkalian antara produksi yang diperoleh dengan jumlah harga jual.Harga jual madu lebah Trigona yaitu Rp125.000,-/kg. Penerimaan rata-rata yang diperoleh dari usaha budidaya lebah madu Trigona sebesar Rp7.550.000,-, setelah total biaya dan penerimaan diketahui maa dapat diperoleh keuntungan rata-rata pada usaha budidaya lebah madu sebesar Rp5.068.900,- per musim panen. Semakin besar keuntungan atau pendapatan yang diperoleh peternak dalam budidaya maka usaha tersebut memiliki prospek untuk dilakukan pengembangan. Sesuai dengan kajian (Elpawati et al., 2015) keuntungan mempunyai peranan yang besar dalam menjamin kesinambungan kegiatan ekonomi. Ini karena mereka yang terlibat dalam kegiatan berkaiatan dengan proses produksi berusaha meningkatkan usaha mereka dari segi pengeluaran atau pengurusan dan sebagainya, untuk menambah keuntungan mereka. Keuntungan bisa diartikan sebagai pertambahan modal dari kegiatan yang diakui seperti perdagangan, perindustrian dan sebagainya setelah dikurangi dengan ongkos produksi dalam usaha. Hal ini akan menjadi tugas setiap peternak yang membudidayakan lebah Trigona $s p$. agar mampu menghasilkan madu yang lebih banyak serta memperoleh keuntungaan yang lebih besar lagi.

\section{Efisiensi Biaya Usaha Budidaya Lebah Madu Trigona sp.}

Efisiensi biaya sangat diperlukan untuk keberlangsungan usaha produk madu Trigona $s p$. hasil budidaya. Menurut (Tasman \& Aima, 2018) petani/peternak adalah sebagai perusahaan murni, yang tujuan utamanya adalah memaksimumkan keuntungan. Efisiensi ekonomi dinyatakan bila sumber daya yang digunakan sebaik mungkin untuk memaksimumkan tujuan yang harus dicapai. Efisiensi biaya usaha budidaya lebah madu sebagai penghasil produk madudapat dilihat pada Tabel 4.

Tabel 4. Analisis efisiensi biaya usaha budidaya lebah madu Trigona sp.

\begin{tabular}{|c|c|c|c|}
\hline Lokasi Bangsal (Desa) & TR (Rp/Tahun) & TC (Rp/Tahun) & $\mathrm{RC}$ ratio \\
\hline Wata Benua & 19.250 .000 & 6.474 .500 & 9,14 \\
\hline Lalonggapu & 13.500 .000 & 3.653 .500 & 3,70 \\
\hline Endanga & 5.000 .000 & 2.277 .500 & 2,20 \\
\hline Jumlah & 37.750 .000 & 12.405 .500 & 15,03 \\
\hline Rata-Rata & 7.550 .000 & 2.481 .100 & 3,01 \\
\hline
\end{tabular}

Sumber: Data Primer Diolah, 2020

Tabel 4. Menunjukkan bahwa rata-rata RC ratio pada usaha budidaya lebah madu Trigona $s p$. menghasilkan RC ratio sebesar 3,01 maka usaha budidaya tersebut menguntungkan dan dilanjutkan. Berdasarkan kriteria pengambilan keputusan, perolehan RC ratio sebesar 3,01 artinya bahwa setiap biaya yang dikeluarkan sebesar 1 maka memperoleh $\mathrm{RC}$ ratio sebesar 3,01 . Semakin tinggi $\mathrm{RC}$ ratio yang diperoleh suatu usaha maka usaha tersebut memliki prospek pengembangan skala yang lebih besar. Hal ini sejalan dengan penelitian yang dilakukan oleh (Rahmayanti et al., 2018) dan (Musdalifa, 2019) bahwa jika RC ratio yang diperoleh lebih besar dari 1 maka usaha budidaya tersebut layak dikembangkan jika dilihat dari biaya yang dikeluarkan dan proporsi penerimaan yang diperoleh lebih besar. 


\section{KESIMPULAN}

Berdasarkan hasil dan analisis data dalam penelitian yang dilakukan di Kecamatan Landono, dapat ditarik kesimpulan bahwa rata-rata produktivitas stup yang diperoleh sebesar 1,02 kg madu per stup. Variasi produktivitas madu yang diperoleh bergantung pada jumlah ketersediaan pakan nektar tiap musimnya, sehingga produktivitas yang diperoleh tiap musim panen juga berubah. Kesediaan pakan menjadi faktor utama dalam kegiatan budidaya lebah madu Trigona sp. Selanjutnya diperoleh Keuntungan rata-rata yang diperoleh dari usaha budidaya lebah madu Trigona sebesar Rp5.068.900,-/tahun. Hasil ini diperoleh dari sejumlah penerimaan dikurangi dengan jumlah biaya total sehingga menghasilkan keuntungan. Untuk efiensi biaya usaha budidaya lebah madu Trigona $s p$. berdasarkan anlisis $\mathrm{RC}$ ratio menghasilkan rata-rata $\mathrm{RC}$ ratio sebesar 3,01 . Perolehan $\mathrm{RC}$ ratio > 1 berarti bahwa usaha budidaya tersebut menguntungkan dan layak untuk dilanjutkan.

\section{REFERENSI}

Bambang, \& Kartasapoetra. (1992). Kalkulasi dan Pengendalian Biaya Produksi. PT Rineka Cipta.

Budiono. (2013). Analisis keuntungan Maksimum Usaha Tambak Udang dalam Pasar Persaingan Sempurna di Kampung Pegat Betumbuk Kecamatan Pulau Derawan. Jurnal Eksekutif, 10(2), 22.

Elpawati, Diasri, F., \& Muhib, A. (2015). Analisis Produksi dan Keuntungan Effectife Mikroorganisme10 (Em-10). Jurnal Agribisnis, 9(2).

Erlangga, G. B. (2016). Analisis Pengaruh Tingkat Pendapatan, Jumlah Tanggungan Keluarga, Tingkat Pendidikan, Usia, dan Lokasi Perumahan Terhadap Permintaan Kredit Pemilikan Rumah Bank BTN (Studi Kasus Kota Malang Tahun 2014). Jurnal IImiah.

Fadhilah, R., \& Rizkika, K. (2015). Laba: Lebah Tanpa Sengat. PT Trubus Swadaya.

Firmansyah, Z. (2015). Analisis Pengaruh Umur, Pendidikan dan Upah Terhadap Produktivitas Tenaga Kerja. Economics Development Analysis Journal, 4(1).

Ichwan, F., Yoza, D., \& Budiani, E. S. (2016). No Title. Jom Faperta UR, 3(2).

Jaya, F. (2017). Produk-Produk Madu dan Hasil Olahannya (Ke-1). UB Press.

Martono, R. V. (2019). Analisis Produktivitas dan efisiensi. PT Gramedia Pustaka Utama.

Musdalifa. (2019). Analisis Produksi dan Pendapatan Usaha Budidaya Lobster di Desa Soropia Kecamatan Soropia. Universitas Halu Oleo Kendari.

Rahmayanti, S. A., Yusuf, M., \& Husni, S. (2018). Kontribusi Usaha Budidaya Lebah Madu (Trigona sp.) terhadap Pendapatan Rumah Tangga Petani di Kecamatan Bayan Kabupaten Lombok Utara. Agroteksos: Agronomi Teknologi Dan Sosial Ekonomi Pertanian, 28(2).

Setiaji, K., \& Fatuniah, A. L. (2018). Pengaruh Modal, Lama Usaha dan Lokasi Terhadap Pendapatan Pedagang Pasar Pasca Relokasi. Jurnal Pendidikan Ekonomi \& Bisnis, 6(1).

Soeharno. (2007). Ekonomi Manajerial. C.V Andi Offeset (Penerbit ANDI).

Soekartawi. (2003). Agribisnis Teori dan Aplikasinya. PT. Raja Grafindo Persada.

Soekartawi. (2016). Usahatani. Universitas Indonesia (UI-Press).

Suhesti, E., \& Hadinoto. (2015). Hasil Hutan Bukan Kayu Madu Sialang di Kabupaten Kampar (Studi Kasus : Kecamatan Kampar Kiri Tengah). Jurnal Kehutanan, 10(2).

Sukirno, S. (2013). Mikroekonomi Teori Pengantar (Ke-3). PT RajaGrafindo Persada.

Tasman, A., \& Aima, H. (2018). Ekonomi Manajerial dengan Pendekatan Matematis. Rajawali Pers.

Tuwo, M. A. (2011). Ilmu Usahatani Teori dan Aplikasi Menuju Sukses. Unhalu Pres.

Warisno. (1996). Budidaya Lebah Madu. Kanisius (Anggota IKAPI). 